\title{
Desarrollo Biotecnológico y Evaluación Fisicoquímica, Microbiológica y Sensorial de un Jugo Funcional, Utilizando (Lactobacillus casei) e Inulina
}

\author{
Iván Patricio Salgado Tello, \\ Cesar Iván Flores Mancheno, \\ Manuel Enrique Almeida Guzmán,
}

Profesor de la Facultad de Ciencias Pecuarias Pecuarias, Escuela de Ingeniería en Industrias Pecuarias, Escuela Superior Politécnica de

Chimborazo, Ecuador

Nataly Geovanna Pusay-Guanga,

Egresada de Ingeniería en Industria Pecuarias, Escuela de Ingeniería en Industrias Pecuarias, Escuela Superior Politécnica de Chimborazo, Ecuador

Doi: 10.19044/esj.2019.v15n6p287 URL:http://dx.doi.org/10.19044/esj.2019.v15n6p287

\section{Resumen}

Le but de l'étude était de déterminer le profil du personnel de radiologie exerçant dans les principales structures sanitaires de Centrafrique et d'y répertorier toutes les installations. C'était étude descriptive réalisée entre le mois d'octobre et le mois de novembre 2018 sous forme d'enquête. L'ensemble du personnel était constitué de 18 praticiens, tous de sexe masculin, avec un moyen de 47,55 ans. La durée moyenne d'années d'expérience était de 12,77ans (extrêmes de 2 à 33 ans). Le personnel était composé de médecins radiologues $(\mathrm{n}=4 ; 22,2 \%)$, des techniciens supérieurs en radiologie et imagerie médicale $(\mathrm{n}=7 ; 38,9 \%)$, des infirmiers diplômés d'Etat (IDE), ( $\mathrm{n}=3 ; 16,7 \%)$ et des assistants de santé (AS), $(\mathrm{n}=4 ; 22,2 \%)$ Il n'existait aucun personnel en matière de radioprotection et de maintenance des installations radiologiques. Le parc radiologique était constitué exclusivement de la radiographie standard et de l'échographie. L'IRM et la TDM ne comptaient pas parmi les installations radiologiques. Le personnel de radiologie et le parc radiologique de Centrafrique ne répondent pas encore aux exigences de la médecine moderne.

Palabras clave: Jugo funcional, Simbiótico, Lactobacillus casei, Inulina 


\title{
Biotechnological Development and Physicochemical, Microbiological and Sensory Evaluation of a Functional Juice, using (Lactobacillus casei) and Inulin
}

\author{
Iván Patricio Salgado Tello, \\ Cesar Iván Flores Mancheno, \\ Manuel Enrique Almeida Guzmán,
}

Profesor de la Facultad de Ciencias Pecuarias Pecuarias, Escuela de Ingeniería en Industrias Pecuarias, Escuela Superior Politécnica de

Chimborazo, Ecuador

Nataly Geovanna Pusay-Guanga,

Egresada de Ingeniería en Industria Pecuarias, Escuela de Ingeniería en Industrias Pecuarias, Escuela Superior Politécnica de Chimborazo, Ecuador

\begin{abstract}
In the ESPOCH, a functional juice was developed and characterized with the addition of Lactobacillus casei and inulin, through a completely randomized design in a bifactorial arrangement of 6 treatments and 3 replications, where the A factor is the type of (free or encapsulated) symbiotic and the B factor is the levels (100, 150 and 200) ppm. Obtaining in all treatments a product microbiologically suitable for consumption, as indicated by the INEN 2337 Standard, where the presence of mesophilic aerobes, molds and yeasts are within the established limits. The physical and chemical analyzes differ significantly in the parameter corresponding to the types of symbiotic but not for the levels. It can be determined that the use of $150 \mathrm{ppm}$ of free symbiotic obtained the best sensory characteristics and the highest growth of Lactobacillus casei, values of $1.05 \mathrm{E}+07 \mathrm{CFU} / \mathrm{ml}$ being determined after 18 days of elaboration, being within the INEN 1334-3 norm.
\end{abstract}

Keywords: Functional juice, Symbiotic, Lactobacillus casei, Inulin

\section{Introduction}

Los alimentos funcionales son aquellos que, a más de aportar nutrientes, nos proporcionan un mejor estado de salud y bienestar. El desarrollo de este tipo de alimentos es una oportunidad de contribuir a mejorar la calidad de la dieta (Olagnero, et al., 2007). 
Actualmente son una de las categorías de alimentos más importantes en el mercado global de la salud y bienestar. El creciente número de personas con intolerancia a la lactosa y el vegetarismo refuerzan la importancia del desarrollo de los productos probióticos no lácteos (Castro, et al., 2017).

En un futuro se preferirán, como está sucediendo actualmente, las bebidas mínimamente procesadas. Una gran proporción de estos productos se destacará por tener una propiedad nutracéutica o funcional (Kac, 2010).

Los probióticos son microorganismos vivos que, ingeridos en cantidades tanto recomendadas como adecuadas, poseen efectos ciertamente beneficiosos para la salud. No obstante, para que estos microorganismos puedan ser probióticos, deben ser de origen humano, no patógenos por naturaleza, resistentes a la destrucción por las secreciones gástricas y biliares, ser capaces de colonizar el tracto gastrointestinal, y ser resistentes a la destrucción por procedimientos tecnológicos (Sánchez et al., 2014).

Las BAL (Bacterias ácido lácticas) son no patógenas, no toxigénicas, Gram positivas, fermentativas, que se asocian a la producción de ácido láctico a partir de carbohidratos, lo que las hace útiles para fermentación de los alimentos. En este grupo se incluyen las especies de Lactobacillus, Lactococcus, y Streptococcus thermophilus, Estos microorganismos no desarrollan olores al crecer en medios comunes, contribuyen a modificar el sabor de alimentos fermentados (Wgo, 2011).

Los Lactobacillus crecen bien en medios ligeramente ácidos, con $\mathrm{pH}$ inicial de 6,4 - 4,5 y con un óptimo de desarrollo entre 5,5 y 6,2. Su crecimiento cesa cuando el $\mathrm{pH}$ alcanza valores desde 3,6 hasta 4,0 en dependencia de especies y cepas, y disminuye notablemente en medios neutros o ligeramente alcalinos (Figueroa, 2006).

Entre los efectos beneficiosos para la salud de las bacterias lácticas se han señalado: una mejor absorción de los nutrientes en los alimentos, la mayoría de los síntomas de intolerancia a la lactosa, la metabolización de algunos fármacos, la caída del colesterol sanguíneo, la disminución de las enzimas implicadas en la cancerogénesis, una mejor motilidad intestinal, la estimulación del sistema inmunitario, la creación de un antagonismo intestinal debido a la producción de inhibidores. Un bloqueo de los sitios de adherencia intestinal de las bacterias patógenas, la inactivación de enteroxinas y la mejoría del estreñimiento (Sanz, 2010).

El Lactobacillus casei es una especie de bacteria anaerobia Gram positiva que se encuentra en el intestino y boca de los humanos. Es productora de ácido láctico, se emplea en la industria láctea en la elaboración de alimentos probióticos. Se ha comprobado que esta especie particular de lactobacilo es muy resistente a rangos muy amplios de $\mathrm{pH}$ y temperatura, siendo además un complemento al crecimiento de Lactobacillus acidophilus, un productor de la enzima amilasa (Jiménez, 2009). 
Los prebióticos son componentes de los propios alimentos que no son absorbidos en el intestino delgado, pero que, al llegar al colon, favorecen el crecimiento y la actividad en sí de las bacterias beneficiosas para el organismo. Benefician al huésped estimulando de forma selectiva el crecimiento y/o actividad de una o un número limitado de bacterias intestinales (Sánchez et al., 2014).

La Inulina es un fructano polidisperso que consiste en una mezcla de oligómeros y polímeros mayores formados por uniones $\beta$-(2-1) fructosilfructosa. El grado de polimerización (GP) proveniente de la achicoria oscila entre 3 y 60, con un valor promedio de aproximadamente 10. Puede ser sintetizada a partir de la raíz de la achicoria y desde la sacarosa a través de la acción de la b-fructo-furanosidasa (origen: Aspergillus Níger). Posee un sabor neutral suave, es moderadamente soluble en agua y otorga cuerpo y palatividad (Olagnero et al., 2007).

Los simbióticos son una mezcla de probióticos y prebióticos destinada a aumentar la supervivencia de las bacterias que promueven la salud, con el fin de modificar la flora intestinal y su metabolismo. Con un efecto sinérgico entre ambos, es decir, los prebióticos pueden estimular el crecimiento de cepas específicas probióticos y por tanto contribuir a la instalación de una microflora bacteriana específica (Cagigas et al., 2002).

Un posible vehículo para la introducción de simbióticos en nuestro organismo de manera natural y mediante nuestra alimentación es el jugo, que es un producto realizado en base a frutas, agua y azúcares. El mango ecuatoriano es de excelente calidad y exquisito sabor, debido a alto contenido de carbohidratos, buen contenido de pro-vitamina A, vitamina B - tiamina, riboflavina, niacina y ácido ascórbico, pocas cantidades de calcio, hierro y fósforo. Además, tienen altos contenidos de otros fitoquímicos que no son nutrientes y confieren un beneficio a la salud (Fundación Mango Ecuador, 2018).

\section{Desarrollo:}

\section{Metodología}

\subsection{Localización y duración del experimento}

El presente trabajo se realizó en el Laboratorio de Procesamiento de Alimentos, Laboratorio de Microbiología de la Facultad de Ciencias Pecuarias y en el Laboratorio de Investigación de la Facultad de Ciencias pertenecientes a la Escuela Superior Politécnica de Chimborazo. Ubicada en el km 1 1/2 Panamericana Sur, el mismo que tuvo una duración de 60 días. 


\subsection{Unidades Experimentales}

La unidad experimental estuvo constituida por 5 litros de jugo de mango, a los cuales se les adicionó un simbiótico libre y un simbiótico encapsulado en concentraciones de 100, 150 y 200 ppm.

\subsection{Tratamiento y diseño experimental}

Se evaluó las características físico químicas, microbiológicas y sensoriales del jugo funcional de mango elaborado con 100, 150 y 200 ppm de producto simbiótico a base de Lactobacillus casei e inulina. Se trabajó con un Diseño Completamente al Azar con un arreglo bifactorial donde el factor A es el tipo de simbiótico y el factor B son los niveles de simbiótico, teniendo para cada uno de ellos 3 repeticiones, como se representa en la Tabla 1.

Tabla 1. Esquema del experimento

\begin{tabular}{|l|l|l|r|r|c|}
\hline Tratamiento & ppm & Codificación & Repetición & T.U.E. & L./Tratamiento \\
\hline \multirow{3}{*}{ Simbiótico libre } & 100 & SL100 & 3 & 5 & 15 \\
\cline { 2 - 6 } & 150 & SL150 & 3 & 5 & 15 \\
\cline { 2 - 6 } & 200 & SL200 & 3 & 5 & 15 \\
\hline \multirow{2}{*}{$\begin{array}{l}\text { Simbiótico } \\
\text { encapsulado }\end{array}$} & 100 & SE100 & 3 & 5 & 15 \\
\cline { 2 - 6 } & 150 & SE150 & 3 & 5 & 15 \\
\cline { 2 - 6 } & 200 & SE200 & 3 & 5 & 15 \\
\hline
\end{tabular}

\subsection{Análisis estadístico y pruebas de significancia}

Los resultados obtenidos fueron procesados en el Software Estadístico SPSS Versión 21, en el que se realizaron los siguientes análisis:

Análisis de varianza (ADEVA). El esquema ADEVA se detalla en la Tabla 2.

Separación de medias según prueba de Duncan a los niveles de $\mathrm{P} \leq 0.05$ y $\mathrm{P} \leq 0.01$.

Análisis de regresión y correlación por el efecto de los niveles.

Tabla 2. Esquema del ADEVA

\begin{tabular}{|l|l|}
\hline Fuente de varianza & Grados de libertad \\
\hline Tipo & 1 \\
\hline Niveles & 2 \\
\hline Tipo * Niveles & 2 \\
\hline Error & 12 \\
\hline Total & 17 \\
\hline
\end{tabular}

\subsection{Procedimiento experimental}

Previo a la realización del experimento para la parte del simbiótico libre se adquirió la cepa liofilizada de Lactobacillus casei (nutrish431®) de CHR HANSEN en la Distribuidora Descalzi S.A. En tanto que la inulina 
Beneo GR se adquirió en la empresa Quifatex. Para su posterior incorporación en el jugo se procedió a la activación de los microrganismos.

Para la realización del jugo con el simbiótico encapsulado, el producto se obtuvo de la investigación denominada "Obtención de un simbiótico encapsulado a base de diferentes niveles de inulina y Lactobacillus casei" de la autoría de la Ing. Sandra Silva. El producto simbiótico encapsulado se añadió directamente al jugo.

\subsubsection{Activación de los microorganismos}

Para la preparación de la solución madre se utilizó 1000 ml de jugo de mango mediante una dilución de agua: pulpa = 1:2.5 (Gasco, 2014).

Al jugo elaborado se le añade (50 mg de Inulina para $100 \mathrm{ppm})$, (75 mg de Inulina para $150 \mathrm{ppm})$ y (100 mg de Inulina para $200 \mathrm{ppm})$. Cómo cofactor se le añade $0,8 \%,(8 \mathrm{~g})$ Fosfato de amonio (Yánez, 2016).

A la solución madre obtenida se le lleva al agitador magnético durante 5 minutos y se traspasa a un frasco termo resistente para esterilizarlo en la autoclave a $121^{\circ} \mathrm{C}$ durante 15 minutos.

Subsiguientemente se enfrió a $37^{\circ} \mathrm{C}$ para añadir el Lactobacillus casei (50 mg para $100 \mathrm{ppm}),(75 \mathrm{mg}$ de para $150 \mathrm{ppm})$ y (100 mg para $200 \mathrm{ppm})$, respectivamente, agitándolo por 5 minutos y luego realizando la incubación en la estufa a $37^{\circ} \mathrm{C}$ por 48 horas.

\subsubsection{Elaboración del jugo de Mango}

Para la elaboración del jugo de fruta se procedió con la recepción de la materia prima (suero de leche fresco, el mango, azúcar y leche condensada), para la posterior selección de mangos en buen estado, desinfección, pelado, licuado y tamizado.

La formulación es una etapa importante en el proceso ya que de esta dependerá la aceptabilidad de los consumidores, los pesos y cantidades que utilizaron se muestran a continuación en la Tabla 3.

Tabla 3. Formulación jugo de mango

\begin{tabular}{|l|l|}
\hline Ingrediente & $\mathbf{\%}$ \\
\hline Suero de leche & 67.7 \\
\hline Mango & 22.6 \\
\hline Azúcar & 7.62 \\
\hline Leche condensada & 2.08 \\
\hline Total & 100 \\
\hline
\end{tabular}

Posterior a la formulación y pesado del jugo se pasteurizo a $70{ }^{\circ} \mathrm{C}$ durante 30 minutos, y luego se enfrió a $37^{\circ} \mathrm{C}$.

Para el tratamiento con el simbiótico libre se mezcló el jugo incubado en relación 1:1 con el jugo recién elaborado (Vela et al., 2011). 
Mientras que para el tratamiento con el simbiótico encapsulado se pesó las partes por millón de simbiótico de acuerdo a los niveles 100, 150 y 200 ppm; y se adicionó directamente en el jugo.

Los jugos resultantes fueron colocados en frascos previamente esterilizados, rotulados y refrigerados a $4{ }^{\circ} \mathrm{C}$.

\subsection{Metodología de evaluación}

La investigación se realizó en la planta de Procesos de Alimentos de la Facultad de Ciencias Pecuarias, donde se elaboró el jugo de mango funcional.

\subsubsection{Parámetros microbiológicos}

Para la determinación de bacterias ácido lácticas se empleó la norma ISO, UNE 4833-1:2014, mientras que para aeróbios mesófilos la norma INEN 1529-5 (2006) y la norma NTE INEN 1529-10 (2010) para mohos y levaduras.

\subsubsection{Parámetros físico químicos}

La determinación del pH se la realizó mediante el método descrito por la norma INEN 1842 (2013), para la acidez se utilizó la norma INEN 750 (2013), mientras que para la densidad se utilizó la norma INEN 391 (2012). En cuanto que para la viscosidad se utilizó la técnica en donde colocamos la aguja número 4 (según la viscosidad del fluido) en el viscosímetro rotacional, luego se enciende el equipo y calibrarlo a $60 \mathrm{rpm}$ y a SPL4, para luego colocar $250 \mathrm{ml}$ de muestra en un vaso de precipitación que será depositado en el equipo, para tomar la lectura resultante (Ariza, 2016).

\subsubsection{Valoración Organoléptica}

Para establecer el grado de aceptación del jugo funcional de mango, utilizamos un método afectivo, aplicando la prueba escalar hedónica verbal, como lo indica la norma ISO 11136.

\section{Discusión}

\section{Microbiológicos}

En la Tabla 4 se puede observar el comportamiento microbiológico del jugo funcional con la adición de Lactobacillus Casei e inulina.

\subsection{Activación del Lactobacillus Casei}

A partir de la activación, se realizó el recuento microbiológico a los 48 días de incubación del microorganismo, con lo cual se halló los valores reportados en la Tabla 4. Existiendo mayor crecimiento de Lactobacillus Casei al utilizar 200 ppm de producto simbiótico. 


\subsection{Bacterias acido lácticas (Lactobacillus casei)}

$\mathrm{Al}$ analizar el jugo funcional elaborado con la adición de Lactobacillus casei e inulina, como se observa en la Tabla 4 se encontraron diferencias altamente significativas $(\mathrm{P}<0.01)$, por efecto del tipo de simbiótico libre y encapsulado, a los 4, 11,18 y 25 días desde la elaboración del jugo.

En el tratamiento con simbiótico libre el Lactobacillus casei, presenta la fase de adaptación hasta los 11 días, entonces comienza la fase exponencial hasta los 18 días, continuando con la fase estacionaria y finalmente a partir del día 18 la población microbiana comienza a morir, al igual que con el simbiótico encapsulado.

Existe crecimiento de Lactobacillus casei a partir de los 11 días en los diferentes niveles de 100, 150 y $200 \mathrm{ppm}$ de simbiótico, teniendo como resultado 4,72E+05 $\mathrm{UFC} / \mathrm{ml}$ para $100 \mathrm{ppm} ; 6,74 \mathrm{E}+05 \mathrm{UFC} / \mathrm{ml}$ para $150 \mathrm{ppm}$ y 7,47E+05 UFC/ml para $200 \mathrm{ppm}$.

A los 25 días de elaboración del jugo se determinó una concentración de microorganismos de 3,24E+06 UFC/ml para $100 \mathrm{ppm}, 3,07 \mathrm{E}+06 \mathrm{UFC} / \mathrm{ml}$ para $150 \mathrm{ppm}$ y $3,98 \mathrm{E}+06 \mathrm{UFC} / \mathrm{ml}$ para $200 \mathrm{ppm}$. Siendo el mejor tratamiento con 150 ppm de simbiótico ya que comenzó con una concentración de microorganismos alta que a su vez se mantuvo en el tiempo.

Según el INEN 1334-3:2011, para que un alimento sea considerado funcional debe contener un número mayor o igual de bacterias viables de origen probiótico a 1 x $106 \mathrm{UFC/g}$ en el producto terminado hasta el final de la vida útil, encontrándose dentro de la norma.

La diferencia en la población microbiana entre los tratamientos con el simbiótico libre y encapsulado, se debe a que el primero fue activado antes de su introducción en el jugo. Existiendo mayor desarrollo microbiano en el tratamiento con el simbiótico libre, ya que se permitió que el Lactobacillus casei se adapte primero a las condiciones del medio para luego sobrevivir en él. Además, el tratamiento con el simbiótico encapsulado estuvo conservado a temperatura ambiente y fue aplicado en la presente investigación después de 30 días de la encapsulación del simbiótico, lo que implicó una reducción de la población microbiana durante su periodo de almacenamiento, pudiendo corroborarse con dos investigaciones indicando que las muestras de microorganismos almacenados a $20^{\circ} \mathrm{C}$, disminuyen su viabilidad a los 21 días de almacenamiento (Molina, 2016).

La reducción del crecimiento microbiano es más frecuente durante el almacenamiento a $25{ }^{\circ} \mathrm{C}$, donde se reducen en aproximadamente 2 unidades logarítmica después de 10 días de almacenamiento (Yeo et al., 2011).

En el presente trabajo los resultados al inicio del periodo de investigación fueron de 6,77E+06 UFC/ml y $1,70 \mathrm{E}+04 \mathrm{UFC} / \mathrm{ml}$ para el simbiótico libre y encapsulado respectivamente. Mientras que a los 25 días 
solamente para el simbiótico libre se obtuvo un recuento microbiano de 6,77E+06 UFC/ml y de 8,37E+04 UFC/ml para el simbiótico encapsulado.

El crecimiento del Lactobacillus casei Shirota en la investigación de viabilidad con una concentración de $7.83 X 107$ [UFC/mL], es superior a la concentración presentada por Lactobacillus Rhamnosus, sin embargo, la disminución de la población es mucho mayor, observándose que a los 8 días de almacenamiento presenta una concentración de 3.30X106 [UFC/mL], la cual disminuye a 106 [UFC/mL] a los 10 días de almacenamiento, presentando una concentración final de 7.33X103 [UFC/mL] a los 20 días de experimentación (Villavicencio, 2006).

El uso de frutas y vegetales como matrices y medios de crecimiento, confiere beneficios al microorganismo probiótico por los diferentes componentes que contienen (Pereira et al.,2011).

\subsection{Mohos y levaduras}

En mohos y levaduras se encontró diferencias altamente significativas por efecto del tipo de simbiótico libre o encapsulado $(\mathrm{P}<0.01)$ a los 4, 18 y 25 días, de elaboración del jugo funcional.

El jugo funcional con el simbiótico libre inicio con $243 \mathrm{UP} / \mathrm{ml}$, al transcurrir el período de investigación, este tipo de microorganismos va disminuyendo debido a que los microorganismos probióticos inhiben la proliferación de los microorganismos patógenos. Como lo indica (James et al., 2017) quien manifiesta que la inulina es un fructooligosacárido cuya función prebiótica contribuye a la proliferación de la micro-flora intestinal y evita el crecimiento de microorganismos patógenos.

Estos resultados son similares a los reportados por (Dicagno et al., 2012) quienes reportaron la presencia de flora acompañante en batidos mixtos de fruta (rojos: cerezas, tomate, moras y ciruelas pasas; verdes: kiwi, hinojo, espinaca y papaya) almacenados a $8,0^{\circ} \mathrm{C}$

En tanto que para el simbiótico encapsulado comenzó con $145 \mathrm{UP} / \mathrm{ml}$ y estos incrementan durante la investigación hasta llegar a $500 \mathrm{UP} / \mathrm{ml}$ a los 25 días. Esto se debe a que las bacteriocinas producidas por el Lactobacillus casei se quedan dentro de la cápsula y no interactúan con el medio.

Según las normas INEN 2337:2008, el jugo de fruta debe contener máximo $1000 \mathrm{UFC} / \mathrm{ml}$, valor superior al encontrado en el estudio, por lo que el producto es apto para el consumo.

Los mohos y levaduras según los niveles de simbiótico del jugo funcional se pueden mencionar que se encontró diferencias altamente significativas $(\mathrm{P}<0.01)$ por efecto de los niveles de simbiótico 100, 150 y 200 ppm para los 4 días de elaboración del jugo funcional. En tanto que para los 11,18 y 25 días no se encontraron diferencias significativas $(\mathrm{P}>0.05)$. 
A los 4 días de elaboración del jugo se presentan valores de 122 UP/ml con 100 ppm, $291 \mathrm{UP} / \mathrm{ml}$ con 150 ppm y $169 \mathrm{UP} / \mathrm{ml}$ con 200 ppm. Mientras que a los 25 días elaboración del jugo encontramos valores $279 \mathrm{UP} / \mathrm{ml}$ con 100 ppm, 185 UP/ml con 150 ppm y 336 UP/ml con 200 ppm. Notándose un incremento en los tratamientos con 100 y 200 ppm pero un descenso de mohos y levaduras en el tratamiento con 150 ppm esto puede deberse a que existió mejor simbiosis.

Al aplicar 100 ppm de producto simbiótico los mohos y levaduras se incrementa en un $17.92 \%$, en tanto que a partir del uso de 150 ppm de producto simbiótico se reduce en $5 \%$. Esto quiere decir que el efecto simbiótico del Lactobacillus casei y la inulina hacen efecto a partir de las 150 ppm.

\subsection{Aerobios mesófilos}

Al realizar los análisis microbiológicos en el jugo funcional elaborado con la adición de L. casei e inulina, se halló diferencias altamente significativas por efecto de los tipos de simbiótico libre y encapsulado a los 3 , 10 y 24 días desde la elaboración del jugo $(\mathrm{P}<0.01)$. Encontrándose en el día 17 diferencias significativas $(\mathrm{P}<0.05)$.

El simbiótico libre inicio con $1670 \mathrm{UFC} / \mathrm{ml}$ mientras transcurrió la investigación disminuyó hasta llegar a $465 \mathrm{UFC} / \mathrm{ml}$. El simbiótico encapsulado comenzó con $451 \mathrm{UFC} / \mathrm{ml}$ y al cabo de los 24 días llego a $195 \mathrm{UFC} / \mathrm{ml}$. Se debe a que en el tratamiento con el simbiótico libre existió un descenso de $\mathrm{pH}$ acompañado de la producción de bacteriocinas.

Según las normas INEN 2337:2008, el jugo de fruta debe contener como máximo hasta $3000 \mathrm{UFC} / \mathrm{ml}$, valor superior al encontrado en el presente estudio por lo que nuestro jugo es apto para el consumo.

En el jugo funcional no encontramos diferencias significativas para ninguno de los niveles 100, 150 y 200 ppm (P>0.05).

Al utilizar 100 ppm de producto simbiótico no se observó disminución de aerobios mesófilos, en cambio en los niveles de 150 y 200 ppm de simbiótico existió un descenso de aerobios mesófilos debido al papel antagónico que realizan los lactobacillus en contra de estos. En concordancia con lo que indica (Heredia et al., 2017), quien menciona que uno de los factores que podría estar involucrado en la actividad antagónica observada de las Bacterias ácido lácticas, podría ser la producción de sustancias tipo bacteriocinas, siendo a nivel biológico además de la producción de bacteriocinas, la exclusión competitiva y la disminución del pH, podrían también estar involucradas en los procesos de antagonismo. Dentro del metabolismo de las bacterias acido lácticas, la producción de ácido láctico y ácidos orgánicos que disminuyen el pH del medio, tienen también un efecto 
importante para inhibir el crecimiento de bacterias sensibles a la acidez, generando el permeado de la membrana de algunas bacterias.

En el caso del simbiótico encapsulado este presenta una mayor población de aerobios debido a que las bacteriocinas y el ácido láctico producidos por el Lactobacillus casei permanecen dentro de la capsula.

Tabla 4. Características microbiológicas del jugo funcional elaborado con la adición de simbiótico a base de Lactobacillus Casei e inulina

\begin{tabular}{|c|c|c|c|c|c|c|c|c|c|c|c|c|c|c|}
\hline \multirow{2}{*}{ Parámetros } & \multicolumn{6}{|c|}{ Tipo } & \multicolumn{8}{|c|}{ Niveles de simbiótico } \\
\hline & Libre & & Encapsulado & & E.E. & Prob. & 100 & & 150 & & 200 & & E.E. & Prob. \\
\hline \multicolumn{15}{|l|}{$\begin{array}{l}\text { Lactobacillus } \\
\text { casei }\end{array}$} \\
\hline 4 días & $1,08 \mathrm{E}+06$ & $\mathrm{a}$ & $1,70 \mathrm{E}+04$ & $\mathrm{~b}$ & $1,31 \mathrm{E}+05$ & 0,000 & $2,80 \mathrm{E}+05$ & $\mathrm{a}$ & $5,35 \mathrm{E}+05$ & $\mathrm{a}$ & $8,35 \mathrm{E}+05$ & $\mathrm{a}$ & $1,60 \mathrm{E}+05$ & 0,087 \\
\hline 11 días & $1,14 \mathrm{E}+06$ & $\mathrm{a}$ & $1,25 \mathrm{E}+05$ & $\mathrm{~b}$ & $5,58 \mathrm{E}+04$ & 0,000 & $4,72 \mathrm{E}+05$ & $\mathrm{~b}$ & $6,74 \mathrm{E}+05$ & $a b$ & $7,47 \mathrm{E}+05$ & $\mathrm{a}$ & $6,83 \mathrm{E}+04$ & 0,038 \\
\hline 18 días & $1,05 \mathrm{E}+07$ & $\mathrm{a}$ & $1,88 \mathrm{E}+05$ & $\mathrm{~b}$ & $1,04 \mathrm{E}+06$ & 0,000 & $3,52 \mathrm{E}+06$ & $\mathrm{a}$ & $6,77 \mathrm{E}+06$ & $\mathrm{a}$ & $5,68 \mathrm{E}+06$ & $\mathrm{a}$ & $1,80 \mathrm{E}+06$ & 0,226 \\
\hline 25 días & $6,77 \mathrm{E}+06$ & $\mathrm{a}$ & $8,37 \mathrm{E}+04$ & $\mathrm{~b}$ & $6,01 \mathrm{E}+05$ & 0,000 & $3,24 \mathrm{E}+06$ & $\mathrm{a}$ & $3,07 \mathrm{E}+06$ & $\mathrm{a}$ & $3,98 \mathrm{E}+06$ & $\mathrm{a}$ & $7,36 \mathrm{E}+05$ & 0,656 \\
\hline \multicolumn{15}{|l|}{$\begin{array}{l}\text { Mohos y } \\
\text { levaduras }\end{array}$} \\
\hline 4 días & $2,43 \mathrm{E}+02$ & $\mathrm{a}$ & $1,45 \mathrm{E}+02$ & $\mathrm{~b}$ & $1,94 \mathrm{E}+01$ & 0,004 & $1,22 \mathrm{E}+02$ & $\mathrm{~b}$ & $2,91 \mathrm{E}+02$ & $\mathrm{a}$ & $1,69 \mathrm{E}+02$ & $\mathrm{~b}$ & $2,37 \mathrm{E}+01$ & 0,001 \\
\hline 11 días & $1,33 \mathrm{E}+02$ & $\mathrm{a}$ & $1,77 \mathrm{E}+02$ & $\mathrm{a}$ & $2,34 \mathrm{E}+01$ & 0,206 & $1,49 \mathrm{E}+02$ & $\mathrm{a}$ & $1,79 \mathrm{E}+02$ & $\mathrm{a}$ & $1,37 \mathrm{E}+02$ & $\mathrm{a}$ & $2,86 \mathrm{E}+01$ & 0,583 \\
\hline 18 días & $5,20 \mathrm{E}+01$ & $\mathrm{~b}$ & $3,56 \mathrm{E}+02$ & $\mathrm{a}$ & $4,06 \mathrm{E}+01$ & 0,000 & $1,92 \mathrm{E}+02$ & $\mathrm{a}$ & $1,76 \mathrm{E}+02$ & $\mathrm{a}$ & $2,43 \mathrm{E}+02$ & $\mathrm{a}$ & $4,97 \mathrm{E}+01$ & 0,622 \\
\hline 25 días & $3,30 \mathrm{E}+01$ & $\mathrm{~b}$ & $5,00 \mathrm{E}+02$ & $\mathrm{a}$ & $4,50 \mathrm{E}+01$ & 0,000 & $2,79 \mathrm{E}+02$ & $\mathrm{a}$ & $1,85 \mathrm{E}+02$ & $\mathrm{a}$ & $3,36 \mathrm{E}+02$ & $\mathrm{a}$ & $5,51 \mathrm{E}+01$ & 0,190 \\
\hline \multicolumn{15}{|l|}{$\begin{array}{l}\text { Aerobios } \\
\text { mesofilos }\end{array}$} \\
\hline 3 días & $1,67 \mathrm{E}+03$ & $\mathrm{a}$ & $4,65 \mathrm{E}+02$ & $\mathrm{~b}$ & $1,43 \mathrm{E}+02$ & 0,000 & $8,65 \mathrm{E}+02$ & $\mathrm{a}$ & $1,10 \mathrm{E}+03$ & $\mathrm{a}$ & $1,24 \mathrm{E}+03$ & $\mathrm{a}$ & $1,75 \mathrm{E}+02$ & 0,342 \\
\hline 10 días & $1,34 \mathrm{E}+03$ & $\mathrm{a}$ & $6,92 \mathrm{E}+02$ & $\mathrm{~b}$ & $1,45 \mathrm{E}+02$ & 0,008 & $1,19 \mathrm{E}+03$ & $\mathrm{a}$ & $8,41 \mathrm{E}+02$ & $\mathrm{a}$ & $1,01 \mathrm{E}+03$ & $\mathrm{a}$ & $1,77 \mathrm{E}+02$ & 0,219 \\
\hline 17 días & $9,48 \mathrm{E}+02$ & $\mathrm{a}$ & $1,12 \mathrm{E}+03$ & $\mathrm{a}$ & $1,97 \mathrm{E}+02$ & 0,542 & $1,29 \mathrm{E}+03$ & $\mathrm{a}$ & $8,38 \mathrm{E}+02$ & $\mathrm{a}$ & $9,85 \mathrm{E}+02$ & $\mathrm{a}$ & $2,41 \mathrm{E}+02$ & 0,435 \\
\hline 24 días & $4,51 \mathrm{E}+02$ & $\mathrm{~b}$ & $1,95 \mathrm{E}+03$ & $\mathrm{a}$ & $1,57 \mathrm{E}+02$ & 0,000 & $1,30 \mathrm{E}+03$ & $\mathrm{a}$ & $8,11 \mathrm{E}+02$ & $\mathrm{a}$ & $1,49 \mathrm{E}+03$ & $\mathrm{a}$ & $1,92 \mathrm{E}+02$ & 0,072 \\
\hline
\end{tabular}

E.E.: Error estándar.

Prob.>0.05: No existen diferencias estadísticas.

Prob. <0.05: Existen diferencias significativas.

Prob. <0.01: Existen diferencias altamente significativas. 


\section{Análisis Físico Químicos}

En la Tabla 5 se puede demostrar el comportamiento del producto en cuanto a sus características físico químicas.

Tabla 5. Características físico químicas del jugo funcional elaborado con la adición de simbiótico a base de lactobacilos e inulina

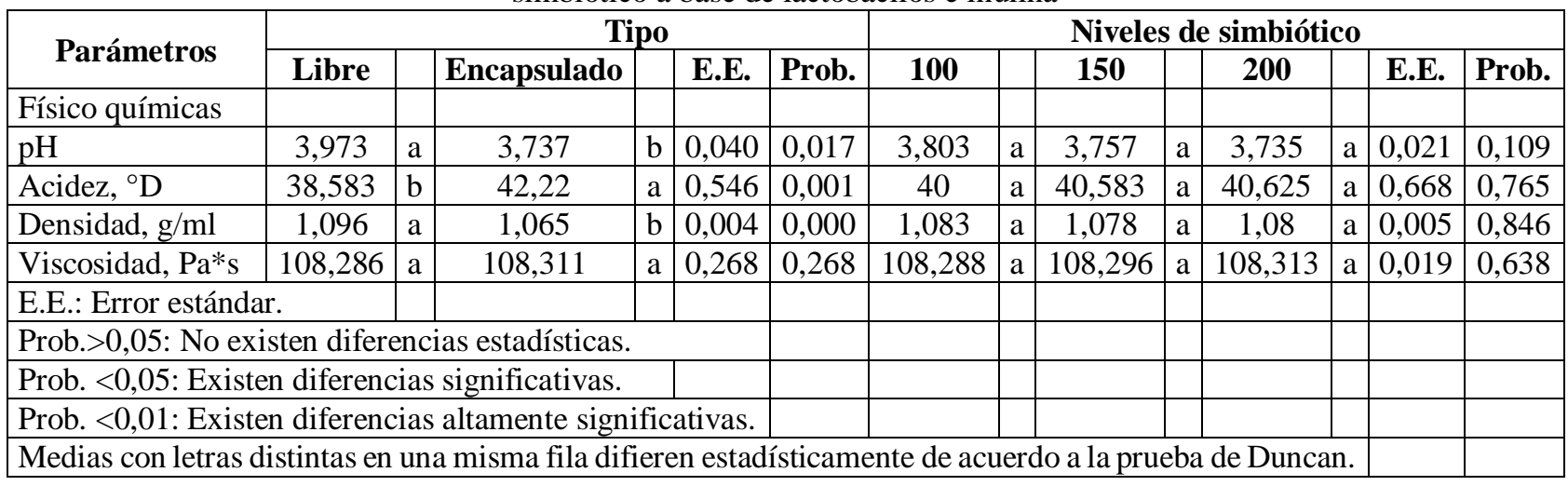

\section{1. $\quad \mathbf{p H}$}

De acuerdo a la Tabla 5 se encontraron diferencias significativas (P $<0.05)$ para el jugo con el simbiótico libre y encapsulado $3,97 \mathrm{pH}$ y 3,73 $\mathrm{pH}$ respectivamente, mientras que por efecto de los niveles de simbiótico no existen diferencias significativas $(\mathrm{P}>0.05)$.

Según las normas INEN 2337:2008, el jugo de fruta debe contener valores inferiores a 4,5 en $\mathrm{pH}$, valor superior al encontrado en el presente estudio, por lo que el jugo se encuentra dentro de los requerimientos.

Según (Vergara, 2017), puede señalar que el pH influye sobre la viabilidad de Lactobacillus casei reduciendo la viabilidad de la bacteria en el tiempo, esto se atribuye a la disminución del pH del medio y de la acumulación del ácido láctico.

\subsection{Acidez, ${ }^{\circ} \mathrm{D}$}

Se encontraron diferencias altamente significativas $(\mathrm{P}<0.01)$ para el jugo con el simbiótico libre y encapsulado $58,38{ }^{\circ} \mathrm{D}$ y $42,22{ }^{\circ} \mathrm{D}$ respectivamente, mientras que para los niveles no existen diferencias significativas $(\mathrm{P}>0.05)$.

En los estudios realizados por (Yoon et al., 2004), el Lactobacillus casei sobrevivió en jugo de tomate a pH bajo de 3,5 y altas condiciones de acidez durante 4 semanas de conservación en cámara frigorífica a $4^{\circ} \mathrm{C}$; se observa una disminución de $\mathrm{pH}$ y un aumento de acidez por formación de ácido láctico. Además, los recuentos de células viables disminuyeron levemente. Este mismo comportamiento se observa en el jugo funcional de mango. 


\subsection{Densidad $\mathrm{g} / \mathrm{ml}$}

Se encontraron diferencias altamente significativas $(\mathrm{P}<0.01)$ para el jugo con el simbiótico libre y encapsulado $1,09 \mathrm{~g} / \mathrm{ml}$ y $1,06 \mathrm{~g} / \mathrm{ml}$ respectivamente. Debido a que la capsula con el simbiótico presento menor densidad, en relación a lo indicado por (Silva, 2018), quien manifiesta en su investigación que no se presentaron diferencias significativas $(P>0,05)$ entre los tratamientos.

A diferencia de los niveles de simbiótico 100, 150 y 200 ppm no existen diferencias significativas $(\mathrm{P}>0.05)$ entre ellos.

Estos resultados permiten deducir que las densidades del encapsulado dependerán de muchos factores uno de ellos del peso molecular del material encapsulante, puesto que mayor peso del mismo mayor será la densidad.

\subsection{Viscosidad, $\mathrm{Pa}^{*} \mathrm{~s}$}

No se encontraron diferencias significativas $(\mathrm{P}>0.05)$ para el jugo con el simbiótico libre y encapsulado, al igual que los niveles.

En investigaciones como la de (Muñoz, 2007), se espera un cambio de viscosidad en el tiempo, debido a la incorporación de prebióticos y/o la producción de exopolisacáridos por las cepas seleccionadas.

\section{Análisis Sensorial}

En la Tabla 6 se puede observar las diferentes valoraciones y apreciaciones que realizarón consumidores afectivos mediante la norma ISO 111363 Sensory analysis - Methodology — General guidance for conducting hedonic tests with consumers in a controlled área.

\subsection{Valoración global}

Como se observa en la Tabla 6, en el jugo funcional se encontraron diferencias altamente significativas $(\mathrm{P}<0.01)$ para los tipos de simbiótico libre y encapsulado, así como para los niveles de simbióticos 100, 150 y 200 ppm.

Calculamos valores de 12,803 y 12,776 para el simbiótico libre y encapsulado respectivamente. Según los niveles de simbiótico aplicados la mayor puntuación 13,97 se alcanzó al utilizar 150 ppm de simbiótico, seguido del tratamiento con $100 \mathrm{ppm}$ con un valor de 12,705 y por último el tratamiento con 200 ppm con 11,69, siendo el mejor tratamiento al utilizar 150 ppm de simbiótico libre, esto puede deberse a que el mismo proporciono un olor ligero acompañado de un leve sabor a fermentado, donde predomina el sabor del mango, la textura de este fue viscosa y homogénea. 
Tabla 6. Valoración de las características organolépticas funcional con la adición de un producto simbiótico a base de lactobacilos e inulina.

\begin{tabular}{|c|c|c|c|c|c|c|c|c|c|c|c|c|c|c|}
\hline \multirow{2}{*}{ Parámetros } & \multicolumn{3}{|l|}{ Tipo } & & & & \multicolumn{5}{|c|}{ Niveles de simbiótico } & & \multirow[b]{2}{*}{ E.E. } & \multirow[b]{2}{*}{ Prob. } \\
\hline & Libre & & Encapsulado & & E.E. & Prob. & 100 & & 150 & & 200 & & & \\
\hline Olor. 5 puntos & 3,157 & $\mathrm{a}$ & 3,151 & $\mathrm{~b}$ & 0,002 & 0,045 & 3,142 & $\mathrm{~b}$ & 3,52 & $\mathrm{a}$ & 2,8 & $\mathrm{c}$ & 0,002 & 0,000 \\
\hline Sabor. 5 puntos & 2,82 & $\mathrm{a}$ & 2,813 & $\mathrm{a}$ & 0,055 & 0,002 & 2,462 & $\mathrm{c}$ & 3,108 & $\mathrm{a}$ & 2,88 & $\mathrm{~b}$ & 0,003 & 0,000 \\
\hline Textura. 5 puntos & 3,423 & $\mathrm{a}$ & 3,414 & $\mathrm{~b}$ & 0,002 & 0,015 & 3,522 & $\mathrm{~b}$ & 3,572 & $\mathrm{a}$ & 3,163 & $\mathrm{c}$ & 0,003 & 0,000 \\
\hline Aspecto. 5 puntos & 3,407 & $\mathrm{a}$ & 3,397 & $\mathrm{~b}$ & 0,002 & 0,008 & 3,58 & $\mathrm{~b}$ & 3,772 & $\mathrm{a}$ & 2,853 & $\mathrm{c}$ & 0,003 & 0,000 \\
\hline Total. 20 puntos & 12,803 & $\mathrm{a}$ & 12,776 & $\mathrm{~b}$ & 0,006 & 0,006 & 12,705 & $\mathrm{~b}$ & 13,972 & $\mathrm{a}$ & 11,692 & $\mathrm{c}$ & 0,007 & 0,000 \\
\hline \multicolumn{13}{|l|}{ E.E.: Error estándar. } & & \\
\hline \multicolumn{13}{|c|}{ Prob.>0,05: No existen diferencias estadísticas. } & & \\
\hline \multicolumn{13}{|c|}{ Prob. $<0,05:$ Existen diferencias significativas. } & & \\
\hline \multicolumn{7}{|c|}{ Prob. <0,01: Existen diferencias altamente significativas. } & & & & & & & & \\
\hline
\end{tabular}




\section{Conclusiones y Recomendaciones}

Al adicionar $150 \mathrm{ppm}$ de simbiótico libre se alcanzó mayor crecimiento de Lactobacillus casei 1,05E+07 UFC/ml en la fase estacionaria, mientras la cantidad de aerobios mesófilos así como los mohos y levaduras no pasaron los límites establecidos por la norma INEN 2337:2008 considerándose un producto apto para el consumo, mientras que en los parámetros físicos químicos se hallaron diferencias significativas de acuerdo al tipo de simbiótico, y no existen diferencias para los niveles. Encontrándose un $\mathrm{pH}$ de 3,97; acidez de 38,58 ${ }^{\circ} \mathrm{D}$; densidad de 1,096 g/ml; viscosidad $108,286 \mathrm{~Pa}^{*} \mathrm{~s}$ para el simbiótico libre mientras que para el encapsulado un $\mathrm{pH}$ de 38,583; acidez de 42,22 ${ }^{\circ} \mathrm{D}$; densidad de 1,065g/ml; viscosidad $108,311 \mathrm{~Pa}^{*}$ s. los mismos que se encuentran dentro de la norma INEN 2337:2008. El jugo funcional de mayor aceptación sensorial se obtuvo al utilizar 150 ppm de simbiótico libre el mismo que alcanzó un puntaje de 13,987/ 20 puntos. Por lo que se recomienda utilizar 150 ppm de simbiótico libre para la elaboración del jugo funcional de mango, ya que presentó buen número bacterias ácido lácticas que contribuyen al alimento en lo que se refiere a las características sensoriales, de conservación, valor nutricional y sus diferentes propiedades metabólicas que posteriormente serán aprovechadas por el consumidor.

\section{References:}

1. Ariza, M. (2016). Comportamiento Reológico De Fluidos Complejos. Materiales Industriales, Ingeniería Técnica Industrial - Mecánica, CIITE.

2. Cagigas, A., \& Anesto, J. (2002). Prebióticos y probióticos, una relación beneficiosa. (Revista Cubana Aliment Nutricion. Instituto de Nutrición e Higiene de los Alimentos) Recuperado de: http://bvs.sld.cu/revistas/ali/vol16_1_02/ali10102 (accedido el 05/03/2018).

3. Castro, C., Díaz, C., \& Gutiérrez, C. (2017). "Probióticos y prebióticos en matrices de origen vegetal: Avances en el desarrollo de bebidas de frutas" Revista Chilena de Nutricion, 44(4), 5-10.

4. DiCagno, R., Minervini, G., Rizzello, G., Angelis, M., y Gobbetti, M. (2011). NCBI: Effect of lactic acid fermentation on antioxidant, texture, color and sensory properties of red and green smoothies. Food Microbiology, 28(5), 750-920.

5. Figueroa, I. (2006). El Beneficio de los probioticos. Iztapalapa: Departamento de Biotecnologia, Universidad Autonoma Metropolitana.

6. Fundación Mango Ecuador. (2018). Exportadores de Mango, Variedades de Mango Ecuatoriano. p. 5. Fundación Mango Ecuador. 
7. G. Kac, G. A. (2010). Epidemiología de la desnutrición en Latinoamérica: situación actual. Nutricion Hospitalaria, 51.

8. Gasco, R. (2014). Elaboración Néctar de Mango. Riobamba: Fundación Mango Ecuador.

9. Heredia, González, \& Vallejo. (2017). "Bacteriocinas de Bacterias Ácido Lácticas" (redalyc.org, Ed.) Red de Revistas Científicas de América Latina y el Caribe, España y Portugal, 42(6). 5-11.

10. INEN 1529-10. (2010). CONTROL MICROBIOLÓGICO DE LOS ALIMENTOS. MOHOS Y LEVADURAS VIABLES. RECUENTOS EN PLACA POR SIEMBRA EN PROFUNDIDAD. Norma Técnica Ecuatoriana.

11. INEN 1529-5. (2006). CONTROL MICROBIOLÓGICO DE LOS ALIMENTOS. DETERMINACIÓN DE LA CANTIDAD DE MICROORGANISMOS AEROBIOS MESÓFILOS. REP. Norma Técnica Ecuatoriana.

12. INEN, 1334.-3. (2011). ROTULADO DE PRODUCTOS ALIMENTICIOS PARA CONSUMO HUMANO. PARTE 3. REQUISITOS PARA LAS DECLARACIONES NUTRICIONALES Y DECLARACIONES SALUDABLES. Norma Técnica Ecuatoriana.

13. ISO 111363:2014 Sensory analysis - Methodology - General guidance for conducting hedonic tests with consumers in a controlled area. First Edition.

14. ISO 4833-1:2014 Microbiología de la cadena alimentaria. Método horizontal para el recuento de microorganismos. Recuperado de https:/www.une.org/encuentra-tu-norma/busca-tunorma/norma/?c=N0052559 (accedido 01/02/2018).

15. James, M., Velastegui, E., \& Cruz, M. (2017). Evaluación de las condiciones de cultivo de Lactobacillus acidophilus y Lactobacillus casei a nivel de laboratorio, con inulina como fuente de carbono. (E. Universidad de las Americas, Ed.) Recuperado de http://www.revistabionatura.com/files/2017.02.01.4.pdf (accedido el 20/12/2017).

16. Jimenez, A. (2009). Efectos de diferentes farmacos sobre el crecimieno de Lactobacillus casei. Instituto Politecnico Nacional, Escuela de Ciencias Biologicas.

17. Molina, M. (2016). Desarrollo de leche de soya en polvo con un ingrediente funcional por medio de la microencapsulacion de cultivos probioticos. Escuela Politecnica Nacional.

18. Muñoz, L. (2007). Diseño Y Evaluación De Una Bebida Funcional En Base A Cranberry Prebiótico Y Probiótico. Universidad de Chile, Facultad de Ciencias Químicas y Farmacéuticas. 
19. NTE INEN 2337. (2008). JUGOS, PULPAS, CONCENTRADOS, NECTARES, BEBIDAS DE FRUTAS Y VEGETALES. REQUISITOS. Norma Tecnica Ecuatoriana.

20. Olagnero, G., Abad, A., Bendersky, S., Genevois, C., Granzella , L., \& Montonati, M. (2007). "Alimentos funcionales: fibra, prebióticos, probióticos y simbióticos” Andeguat, 25(121), 6-14.

21. Pereira, F., y Maciel, C. (2011). Elsevier: Probiotic beverage from cashew apple juice fermented with Lactobacillus casei. Food Research International, 44(5), 1276-1283.

22. Sanchez, E., Laguno, I., \& Garcia, J. (2014). Alimentación Equilibrada. I.E.S. Martínez Uribarri.

23. Sanz, B. (2010). Alimentacion probiotica y bacterias lacticas. Facultad de Veterinaria, Universidad Computense de Madrid, 3.

24. Silva, S. (2018). "Obtenciòn De Un Simbiòtico Encapsulado A Base De Diferentes Niveles De Inulina Y Lactobacillus Casei” Espoch, Escuela de Ingenieria en Industrias Pecuarias.

25. Vela, G., \& Castro, M. (2011). Bebida probiótica de lactosuero adicionada con pulpa de mango y almendras. Universidad de Ciencias y Artes de Chiapas.

26. Vergara, A. (2017). Estudio de la Viabilidad de Lactobacillus casei. Universidad Austral De Chile, Facultad De Ciencias Agrarias, Escuela De Ingeniería En Alimentos.

27. Villavicencio, L. (2006). Viabilidad de Lactobacillus casei Shirota y Lactobacillus rhamnosus en Jugo de Cranberry. Universidad Austral De Chile- Escuela De Ingenieria En Alimentos.

28. WGO.(2011). Probióticos y prebióticos. Guías Mundiales de la World Gastroenterology (Organización Mundial de Gastroenterología) Recuperado de http://www.worldgastroenterology.org/UserFiles/file/guidelines/probi otics-spanish (accedido el 04/03/2018).

29. Yeo, S., Ewe, J., \& Liong, M. (2011). "Carries of Probiotics Biology" Genetics and Health Aspects, 21(1), 191-220.

30. Yoon, K., Woodams, E., \& Hang, Y. (2004). Probiotication of Tomato Juice by Lactic Acid Bacteria. The Journal of Microbiology, 42(4). 